\title{
An Exploratory Study on Open Conversation Spaces in Software Engineering
}

\author{
Kevin Dullemond \\ Delft University of Technology \\ IHomer \\ The Netherlands \\ k.dullemond@tudelft.nl
}

\author{
Ben van Gameren \\ Delft University of Technology \\ IHomer \\ The Netherlands \\ b.j.a.vangameren@tudelft.nl
}

\author{
Rini van Solingen \\ Delft University of Technology \\ The Netherlands \\ d.m.vansolingen@tudelft.nl
}

\begin{abstract}
Software engineering is by nature a highly collaborative activity and being able to collaborate effectively is a key factor for project success. However, collaborating effectively in Global Software Engineering, in which team members are geographically, temporally and socio-culturally separated from each other, is an important challenge. In a traditional colocated Software Engineering setting, one of the most important communication patterns is a conversation. Technological support to have conversations in a distributed setting is commonly used, however overhearing conversations of your colleagues is mostly not feasible with these tools. To explore the importance of overhearing conversations we conducted a focus group and a questionnaire in a large international software development company. In this paper we report on the qualitative data from the focus group and the quantification of this data researched with the questionnaire. Based on these findings we will make recommendations on how to support overhearing conversations in Global Software Engineering.
\end{abstract}

Index Terms-Conversations, Overhearing, Open Conversation Space, Collaborative Software Engineering, Case Study, Focus Group, Survey, Questionnaire

\section{INTRODUCTION}

In this paper we will report on the first part of an empirical study about overhearing conversations and how to support this. This first part of the study concerns the evaluation of being able to overhear conversations of your colleagues in the field of Software Engineering. The second part of the study will concern the evaluation of overhearing conversations in a distributed setting and will be discussed in a future publication. We are interested in an evaluation of the value of overhearing conversations because this is often infeasible in distributed settings and could be one of the causes of the challenges faced when working in such a setting.

The objective of this paper is: To provide evidence that research about support for overhearing conversations is worth pursuing and to provide insights on important aspects to consider when doing so. Therefore, we:

- Determine the benefits and challenges of having insight in the active conversations and determine how important these are

- Determine what information about a conversation is important and determine how important this is

- Determine what actions can be carried out on a conversation and determine how important they are
- Determine the benefits and challenges of having access to conversations after they end and determine how important these are

The remainder of this paper will be structured as follows. In the next section we will present background information about Global Software Engineering, awareness issues in such settings and the overhearing of conversations. Following this we will discuss the research site and our methods of data collection and analysis. Subsequently we will present our findings in the findings section and reflect upon the results and discuss limitations in the discussion section. Finally we will conclude upon our work in the conclusions section and discuss future research opportunities.

\section{BACKGROUND}

It is becoming increasingly common for collaborative Software Engineering teams to no longer conduct their work from a single office building. This happens both due to the globalization of business [1], [2], [3] and because people are starting to work from home more and more [4]. Advantages of the globalization of business include: market-proximity [5], [6], reducing time-to- market by working around the clock [1], [7], flexibility with respect to business opportunities [1], [8], reducing costs by delegating work to countries with low labor cost [9], [6] and being able to fully utilize available resources [2], [6]. Advantages of working from home include: increased autonomy [10], increased flexibility [10], increased productivity [11], increased motivation [12] and improvement in the quality of the environment [10]. Since team members do not share a physical work environment when working distributed from each other, information exchange between them becomes infeasible without technological support. This information exchange, however, is necessary to acquire knowledge about the context in which you are working. This knowledge is essential in collaborative work to properly cooperate with others [13], [14] and is commonly referred to as 'awareness' [13], [15]. In general, however, the technological support used to acquire awareness (such as telephone or email) is inferior to the way contextual information is shared in a traditional colocated setting, because in comparison it (i) takes more effort since the communication is more intentional [16], (ii) is more 
obtrusive [17], (iii) happens less frequently [18], [19] and (iv) contains less information [16], [20].

One of the most important communication patterns that occur in a traditional office setting are conversations [21]. Dullemond et al. [22] define a conversation in the context of Global Software Engineering as: "An exchange of information between two or more people where those participating use synchronous communication directed at the other participants". So, for example, broadcasting information, like an announcer at a football stadium, at a train station or at the market place is not having a conversation. Another example of something which is not a conversation by this definition, is an email exchange since the sending and receipt of information in a such an exchange cannot be regarded as instantaneous: the communication is not synchronous. Conversations are important to integrate and coordinate work [23], [24], [25], share existing knowledge [26], [27] and create new knowledge [28], [26], [27]. When working in a distributed setting having conversations is supported by IM-tools, audio conferencing and video conferencing. However, it is not only important to have conversations yourself, but it is also important to overhear the conversations of others [22]. Firstly, this provides access to the information which is discussed in these conversations [24]. Secondly, having insight in the ongoing conversations provides the opportunity to join a conversation and take advantage of the benefits this offers [29]. Finally, by having access to the communication frequencies between colleagues, the insight into the communication structure of the project team is increased [30], [31], [32]. Dullemond et al. [22] use the term Open Conversation Space to denote a space in which the actors can have conversations and where these conversations can be overheard by the other actors in that space. We will use this notion in this paper as well.

\section{Research Site AND Method}

\section{A. Site}

Participants in the study were a group of Software Engineers at Exact, a Software development company operating in 40 countries. Exact offers Enterprise Resource Planning software for medium-sized and small businesses. At the end of 2010 it employed 1867 employees worldwide and 359 in the Netherlands alone [33]. The specific group of employees that were involved in the study worked on a product called Exact Online which is offered as a service (SaaS). As for now this product is targeted at the lower end of the SME market and is being introduced in the Netherlands in 2005. The majority of the people in this group worked from the Delft (The Netherlands) office and was co-located on a single floor. However, also three people from the Wemmel (Belgium) office participated as well as two from the Minneapolis (USA) office. Next to this, people worked from home fairly often and frequently communicated using Instant Messaging software even when working from the same office. During the case study they also used a tool called Communico (see [34] for a video demonstration and [35] for a more thorough explanation) which makes it possible to overhear Instant Messaging conversations.
The group of people that participated in the study is in our opinion appropriate for reaching the research objectives described in the introduction. Firstly, software engineering is naturally a team activity. Software engineers need to collaborate effectively in order to deliver a project on time, on budget and to an appropriate quality level [36]. Secondly, the group of people consisted of experienced software engineers with an average of 10 years of experience in the field. Thirdly, the group of people we studied is both experienced with collaborating in a co-located setting and in a distributed setting. Finally, the group also used Communico and therefore gained familiarity with the concepts researched in the study.

\section{B. Data Collection and Analysis Methods}

To reach our research objectives we used two methods to acquire the empirical data in this study. Firstly we performed an 8-person focus group to determine the benefits, challenges, information items and possible actions asked for in the research goals. Following this we performed a questionnaire among 44 participants to determine the relative importance of these benefits, challenges, information items and possible actions. Next, we will explain for both the focus group and the questionnaire, why we chose to use that method of data collection, give details about its execution and discuss how we analyzed the data we gathered.

\section{Focus Group}

Kontio et al. [37] describe focus groups as "carefully planned discussions, designed to obtain the perceptions of the group members on a defined area of interest". A focus group usually consists of 3 to 12 participants and the discussion is guided and facilitated by a moderator, who follows a predefined structure so that the discussion stays focused. The participants of a focus group are selected via purposive-sampling: they are chosen based on their individual characteristics. The group setting enables the participants to build on the responses and ideas of the others, which increases the richness of the information gained [38]. Strengths of a focus group include the ability to discover new insights, offering the opportunity to explore in-depth why participants think the way they do, and being a cost efficient way of obtaining practitioner experience [39], [37]. However, it also shares weaknesses with many other qualitative methods. Firstly, it may be difficult to generalize the results due to the limited number of participants [40], [39]. Secondly, group dynamics, communication styles and the social acceptability of certain topics and opinions can influence the discussion and therefore introduce bias [39], [37]. Thirdly, it is possible that participants have hidden agendas, for example: trying to come across favorably [37]. Finally, some of the participants might not completely comprehend the topics discussed [37].

In this study the goal of the focus group was to elicit the benefits, challenges, information items and possible actions. We chose to do a focus group because the method is appropriate for discovering new insights, exploring in-depth why participants think the way they do and because the method 
requires a limited amount of time of the participants. We performed the focus group in approximately 2.5 hours with 8 people from the site we discussed in the previous subsection. We chose to use participants that actively participated in the use of Communico. We chose these people because they are more likely to have thought about the subject we wished to discuss and because they are motivated to contribute, which is also important in an interactive format such as a focus group. About 2 weeks before the focus group we invited the participants to take part by e-mail invitation. In this e-mail we explained what a focus group entails, what was expected of them and the goal of the focus group. We also emphasized that our interest would lay in their opinions and insights, we would merely be there to observe and moderate and the importance of them all contributing to the discussion roughly equally. Finally, we also sent them a short introduction on what topics we were going to discuss.

During the focus group itself the first two authors were present. One of the authors took the role of moderator, so he made sure the conversations stayed on topic, the structure ${ }^{1}$ was followed and all participants in the focus group contributed roughly equally to the discussion. The other author mainly took notes and assisted the moderator when necessary. We chose to have the main moderator not take notes because being a moderator requires focus and taking notes can distract him from this activity [38]. In carrying out the focus group we followed a structured approach to ensure we would discuss the topics on which we wanted to elicit opinions. After we introduced the focus group itself and repeated the goals and ground rules, we started by identifying the benefits and challenges of having insight in active conversations. Following this, we identified what information and what actions are important when a conversation is taking place. Finally, we also identified the benefits and challenges of having access to the finished conversations.

The identification of the benefits, challenges, information items and actions was carried out as follows: First we would shortly introduce each subject and subsequently we would hand out sticky notes and ask a question we wanted to know the groups opinion about. Following this, everyone would write answers on sticky notes individually after which we would gather all the sticky notes and discuss each one with the entire group. In the discussion of each sticky note we determined what was meant by it and merged it with, or linked it to various other sticky notes if appropriate, to try and create an overall group consensus.

To conclude the discussion about the focus group we will discuss how we dealt with the challenges of using a focus group to gather data. Firstly, because we defined and followed a predefined structure we were able to control the overall content of the focus group sufficiently and make sure group dynamics did not steer the discussion in an undesirable direction. When a certain discussion did seem to drag on too long without progress the moderator would step in and

\footnotetext{
${ }^{1}$ http://Aspic.nl/OCS/FocusGroupGuide.pdf
}

gently move the discussion onwards. We also dealt with the challenge of social acceptability. For one, we repeatedly emphasized the importance that everyone contributed to the conversation. This point seems to have come across well, as everyone really contributed to the discussions. Another thing we did to deal with this, was the use of sticky notes. Because this method forces everyone to think about a question on their own first and write down their opinions, the temptation to agree with the loudest person or the first person to voice his opinion is reduced. Finally, we performed the focus group in a separate closed office to protect the focus group from outside influences. A third challenge we dealt with concerns that the comprehension of the topic by the participants can be too limited to have an in depth discussion. We dealt with this by choosing motivated participants who had experience with the topic as they used Communico frequently. Next to this, we also sent an introduction into the focus group and the topics discussed in advance and repeated this also in a short presentation right before the focus group started. Finally, the challenge of hidden agendas is not likely to apply in this case study because of the nature of the project. The participants had no logical interest in influencing the outcome of our research as the goals of the research were purely academic with no direct business related decisions depending on it. Overall the focus group worked well and the findings will be discussed in the findings section.

\section{Questionnaire}

Fink [41] describes surveys as: "a system for collecting information from or about people to describe, compare or explain their knowledge, attitudes or behavior". When conducting a survey it is possible to collect information directly, by interviewing people, or indirectly by reviewing written, oral and visual records of people's thoughts and actions. The most used method to do this is a questionnaire [42], in which participants are asked a series of questions for example via filling in a written form, responding to an email or answering the questions on a specifically designed web page. Strengths of gathering data by use of a questionnaire include that the method is quick and requires little effort compared to other methods, that the use of standardized answers simplifies the analysis of data and that respondents can complete the questionnaire when it suits them [43]. Weaknesses are mainly concerned with the quality of the data, both with respect to the completeness and the accuracy. Questionnaires typically have low response rates, have difficulties with motivating the respondents to provide accurate answers, are bounded in the amount and complexity of questions they can ask, are bounded to asking questions and assume people have readily available answers to these questions [43].

In this study we elected to use a questionnaire to determine the mutual importance of the qualitative data we elicited in the focus group. We researched questions such as: "Which advantages of overhearing conversations are most important?" and "Is knowing the subject of a conversation more important when participating in a conversation than when you are merely 
listening to a conversation?". We chose to use a questionnaire to do this because this made it possible for us to include the opinions of a larger group of people than if we used another method and because it is possible to research such questions by using a standardized set of questions. In the questionnaire we asked the respondents to rate the various advantages, challenges, information items and actions on a 5point Likert scale [44] with a no-opinion option. We included a no-opinion option to prevent people with no opinion on a specific question to answer it anyway and 'pollute' the data in this fashion [39].

In this questionnaire the population is the Exact Online department. We chose to send the questionnaire to the 47 people who installed Communico (out of the 61 that were approached). We chose to send the questionnaire to this sample of the population because we felt these people would be most motivated to complete the questionnaire since they were interested enough to install the tool. Sampling in this fashion to try and achieve a high response rate is known as convenience sampling [42]. We do not think we significantly bias the results by sampling like this because half of the people we sent the questionnaire to (23 out of 47) used the tool for less than 20 hours in a 4-month period. Therefore, it is plausible to assume sufficient people with a general negative view on the concepts are recruited for the sample to accurately represent the population.

We sent the questionnaire ${ }^{2}$ via e-mail, handed out print outs and also made a web-form available to try and make it as convenient as possible for respondents to return the questionnaire. Other methods we used to maximize the return rate were the personalization of the request, the sending of follow-up requests, asking people in person to get their sympathy and convince them they can make a difference, and the already mentioned convenience sampling. In the end, 44 out of the 47 people we approached returned the questionnaire, so the response rate was 94\%. To increase the accuracy of the data we tried to avoid common pitfalls in performing questionnaires like: double-barreled questions, ambiguous questions and leading questions [39]. The results of the questionnaire can be found in anonymized form at http://Aspic.nl/OCS/QuestionnaireData.xls.

We analyzed the data as follows: In the questionnaire we asked the respondents to rate the various advantages, challenges, information items and actions. We used this data to reflect on the mutual importance of these. So, for example, we compared the importance of the benefits of overhearing conversations. In order to do so, we applied the Fisher's Least Significant Difference (LSD) method [45] on each of the following categories: benefits of overhearing conversations, challenges of overhearing conversations, information about a conversation, actions possible on a conversation, benefits of finished conversations and challenges of finished conversations. This method first applies the non-parametric Friedman

\footnotetext{
${ }^{2}$ http://Aspic.nl/OCS/Questionnaire.pdf
}

test $^{3}$ in order to determine if the items of the data set of a specific category are significantly different. If the result of applying the Friedman test indicates this is the case, we apply the non-parametric Wilcoxon matched-pairs signed-rank test ${ }^{4}$ to pairwise compare all items in that category. From the results of this test it can be concluded whether or not it is likely one of the variables is rated as more important. In the next section we will discuss the results of this analysis.

\section{FINDINGS}

In this section we will present the findings of the empirical study. To do this in a clear and concise fashion, we will structure this section in four parts, one for each of the research objectives. For each of these research objectives we will first qualitatively describe our findings. So, we will describe the benefits, challenges, actions and information items respectively. Following this we will discuss the relative importance of these, by presenting the quantitative data we gathered and our analysis of this data. For each of the comparisons we make we will report the result of the Friedman test and if this test passes we will present a table summarizing all Wilcoxon tests we performed. In this table a green 'larger than'-sign means the Wilcoxon test passed and the item on the left is rated as more important to a statistically significant level. When the test fails we cannot conclude anything regarding the mutual importance and we show a red ' $X$ '. In these tables the items that are compared are ordered based on an intermediary ranking of these, produced when applying the Friedman method. The complete result of all tests can be found in non-summarized form at http://Aspic.nl/OCS/QuestionnaireDataAnalysis.pdf. In this document the Likert scale values from the questionnaire are represented as a value between 1 and 5, 1 meaning '- -', and 5 meaning ' ++ '.

\section{A. Benefits and challenges of overhearing conversations}

\section{Benefits}

The benefits of having insight in the active conversations we found in the focus group are the following:

- Having access to the technical knowledge of colleagues

- Acquiring involvement with colleagues

- Enjoying your work

- Being able to join a conversation

- Acquiring insight in the communication structure of the team

\author{
Technical \\ Knowledge \\ Involvement \\ Enjoying \\ Joining \\ Communication \\ Structure
}

An overview of how these benefits were rated in the questionnaire is shown in table I.

When applying the Friedman test on this data set it showed the variables are likely to come from a different distribution $\left(\chi^{2}(4)=9.806, P=0.044\right)$. So, we applied the Wilcoxon

\footnotetext{
${ }^{3}$ http://faculty.vassar.edu/lowry/ch15a.html

${ }^{4}$ http://faculty.vassar.edu/lowry/ch12a.html
} 
TABLE I

DESCRIPTIVE STATISTICS - BENEFITS OF OVERHEARING CONVERSATIONS

\begin{tabular}{|l|c|c|c|c|c|}
\hline \multirow{2}{*}{} & \multicolumn{2}{|c|}{ N } & \multicolumn{3}{c|}{ Interquartile range } \\
\cline { 2 - 6 } & Opinion & No-Opinion & 25 th & 50 th & 75 th \\
\hline Technical_Knowledge & 44 & 0 & $-/+$ & + & ++ \\
\hline Involvement & 44 & 0 & $-/+$ & + & + \\
\hline Enjoying & 43 & 1 & - & + & + \\
\hline Joining & 44 & 0 & $-/+$ & + & + \\
\hline Communication_Structure & 42 & 2 & - & $-/+$ & + \\
\hline
\end{tabular}

test on all pairs of 2 variables in the data set to check if we could conclude anything about their mutual importance. The results of these tests are summarized in table II.

TABLE II

COMPARATIVE ANALYSIS - BENEFITS OF OVERHEARING CONVERSATIONS

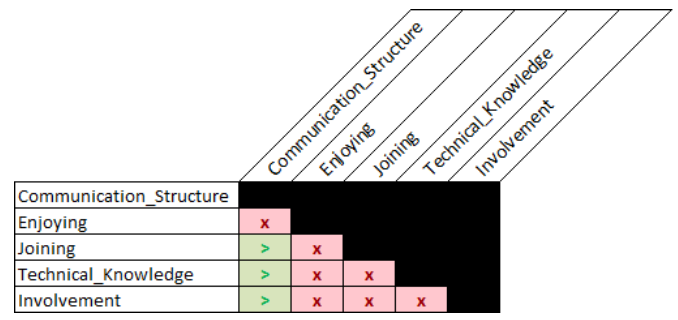

From this table we may conclude that Technical knowledge $(\mathrm{Z}=-2.347, \quad \mathrm{P}=0.019), \quad$ Involvement $\quad(\mathrm{Z}=-2.515, \quad \mathrm{P}=0.012)$ and Joining $(\mathrm{Z}=-2.135, \mathrm{P}=0.033)$ are more important than Communication structure.

\section{Challenges}

The challenges of having insights in the active conversations we found in the focus group are the following:

- It can be distracting from the current Distracting work activities

- The context of the conversation can Context be unclear

- The information is volatile

Volatile

- A lack of control for the people Lack of whose conversations are overheard Control

An overview of how these challenges were rated in the questionnaire is shown in table III.

TABLE III

DESCRIPTIVE STATISTICS - CHALLENGES OF OVERHEARING CONVERSATIONS

\begin{tabular}{|l|c|c|c|c|c|}
\hline \multirow{2}{*}{} & \multicolumn{3}{|c|}{ N } & \multicolumn{3}{c|}{ Interquartile range } \\
\cline { 2 - 6 } & Opinion & No-Opinion & 25 th & 50 th & 75 th \\
\hline Distracting & 43 & 1 & $-/+$ & + & ++ \\
\hline Context & 43 & 1 & $-/+$ & + & + \\
\hline Volatile & 44 & 0 & - & + & + \\
\hline Lack_Of_Control & 43 & 1 & - & $-/+$ & + \\
\hline
\end{tabular}

When applying the Friedman test on this data set it showed the variables are likely to come from a different distribution $\left(\chi^{2}(4)=13.511, P=0.004\right)$. So, we applied the Wilcoxon test on all pairs of 2 variables in the data set to check if we could conclude anything about their mutual importance. The results of these tests are summarized in table IV.

TABLE IV

Comparative ANALYSIS - CHALlENGES OF OVERHEARING CONVERSATIONS



From this table we may conclude that Distracting and Context are more important than Volatile and Lack Of Control.

\section{B. Information about a conversation}

The important types of information about a conversation we found in the focus group are the following:

- Who are Participating in the con- Participating versation

- Who are viewing the conversation Viewers

- The complete factual content

content

- The Commitment of a participant Commitment

- The Contribution of a participant Contribution

- The subject of the conversation Subject

- The tone of the conversation Tone

- The type of the conversation Type

- The phase the conversation is in Phase

- The location the conversation Location takes place

- The accessibility of the conversa- Accessibility tion

In the questionnaire we asked to rate the importance of these information items based on ones involvement in the conversation. Involvement in a conversation has to do with how aware someone is of a conversation and whether he participates in the conversation. Dullemond et. al [22] define an model of conversation involvement based on this, which is shown in figure 1 . In the questionnaire we have asked the

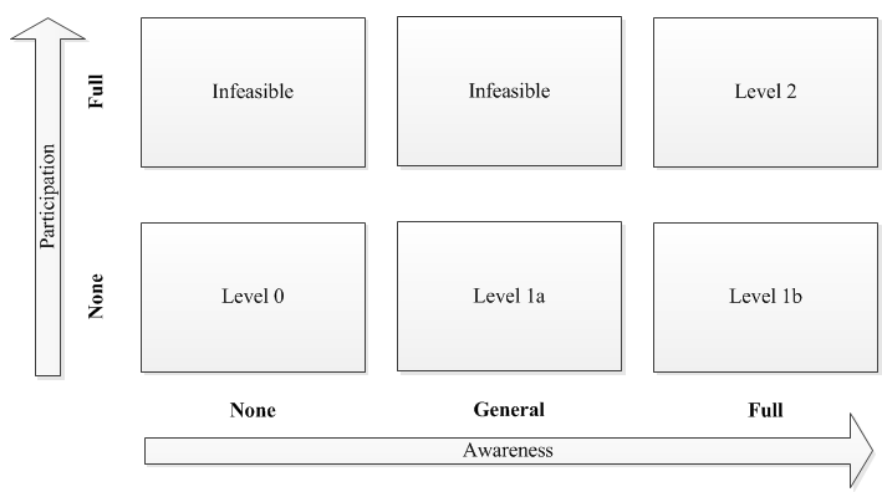

Fig. 1. Model of conversation involvement [22] 
TABLE V

DESCRIPTIVE STATISTICS - INFORMATION ITEMS

\begin{tabular}{|c|c|c|c|c|c|c|c|c|c|c|c|c|c|c|c|}
\hline & \multicolumn{5}{|c|}{ Overhearing } & \multicolumn{5}{|c|}{ Listening } & \multicolumn{5}{|c|}{ Participating } \\
\hline & \multicolumn{2}{|c|}{$\mathrm{N}$} & \multicolumn{3}{|c|}{ Interquartile range } & \multicolumn{2}{|c|}{$\mathrm{N}$} & \multicolumn{3}{|c|}{ Interquartile range } & \multicolumn{2}{|c|}{$\mathrm{N}$} & \multicolumn{3}{|c|}{ Interquartile range } \\
\hline & Opinion & No-Opinion & 25th & 50th & 75th & Opinion & No-Opinion & 25th & 50th & 75th & Opinion & No-Opinion & 25 th & 50th & 75th \\
\hline Subject & 43 & 1 & $-1+$ & + & ++ & 43 & 1 & + & + & ++ & 44 & 0 & + & ++ & ++ \\
\hline \begin{tabular}{|l|} 
Participants \\
\end{tabular} & 43 & 1 & $-1++$ & + & + & 43 & 1 & $-1+$ & + & ++ & 44 & 0 & + & + & ++ \\
\hline Content & 41 & 3 & $-1+$ & + & + & 42 & 2 & + & + & ++ & 44 & 0 & + & + & ++ \\
\hline Contribution & 41 & 3 & - & $-1+$ & + & 42 & 2 & $-1+$ & + & + & 44 & 0 & + & + & ++ \\
\hline Commitment & 41 & 3 & - & $-1+$ & + & 41 & 3 & $-1+$ & + & + & 43 & 1 & + & + & ++ \\
\hline Tone & 41 & 3 & $-1+$ & + & +H & 42 & 2 & $-1+$ & + & + & 43 & 1 & + & + & ++ \\
\hline Type & 41 & 3 & $-1++$ & + & ++ & 42 & 2 & + & + & ++ & 43 & 1 & + & + & + \\
\hline Accessibility & 39 & 5 & $-1+$ & + & ++ & 40 & 4 & $-1+$ & + & ++ & 41 & 3 & $-1+$ & + & +H \\
\hline Phase & 41 & 3 & $-1+$ & $-1+$ & + & 41 & 3 & $-1+$ & + & + & 41 & 3 & $-1+$ & + & ++ \\
\hline \begin{tabular}{|l} 
Viewers \\
\end{tabular} & 41 & 3 & - & - & $-1+$ & 41 & 3 & - & $-1+$ & $-1+$ & 42 & 2 & $-1+$ & $-1+$ & + \\
\hline \begin{tabular}{|l} 
Location \\
\end{tabular} & 42 & 2 & $\ldots$ & - & $-1+$ & 41 & 3 & $-1+$ & + & + & 43 & 1 & $\ldots$ & $-1+$ & $-1+$ \\
\hline
\end{tabular}

participants to rate the importance of the various information items in three of these levels:

- Overhearing a conversation

Level la

- Actively listening in on a conversation

Level 1b

- Participating in the conversation

Level 2

An overview of this rating is shown in table $\mathrm{V}$.

Because in this case we have two dimensions (the information items and the levels of involvement) instead of one we have analyzed this data more extensively. Firstly, similarly to the analysis in the previous subsection, we have compared the relative importance of the information items in each of the 3 levels of involvement. For all three of these, the Friedman test passed (respectively $\chi^{2}(10)=117.712, P=0.000, \chi^{2}(10)=$ $122.639, P=0.000$ and $\left.\chi^{2}(10)=101.088, P=0.000\right)$ and the results of the Wilcoxon comparisons are shown in tables VI, VII and VIII respectively.

TABLE VI

COMPARATIVE ANALYSIS - INFORMATION ITEMS OF OVERHEARING A CONVERSATION

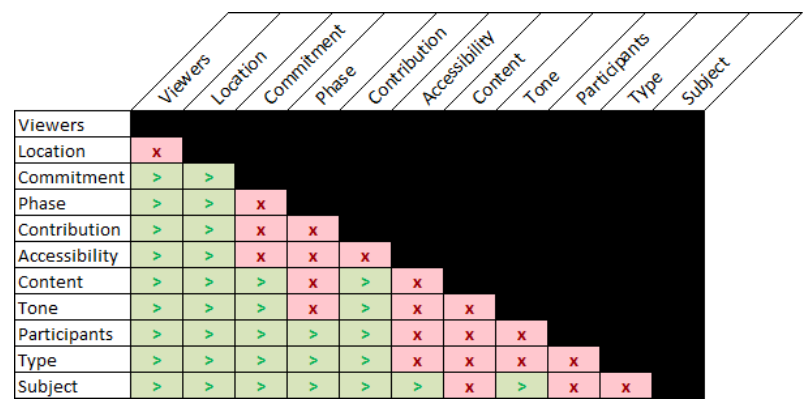

From these tables the relative importance of the different information items can be seen for each of the levels of involvement. So, for example, from table VI it can be concluded that when overhearing a conversation the Participants are more important than the Viewers, Location, Commitment, Phase, Contribution and Accessibility. Another example is that when participating Commitment is more important than Location, Viewers and Phase.

Following this, we also compared the rating of each of these items in the different levels of involvement. The Friedman test
TABLE VII CONVERSATION



TABLE VIII

COMPARATIVE ANALYSIS - INFORMATION ITEMS OF PARTICIPATING IN A CONVERSATION

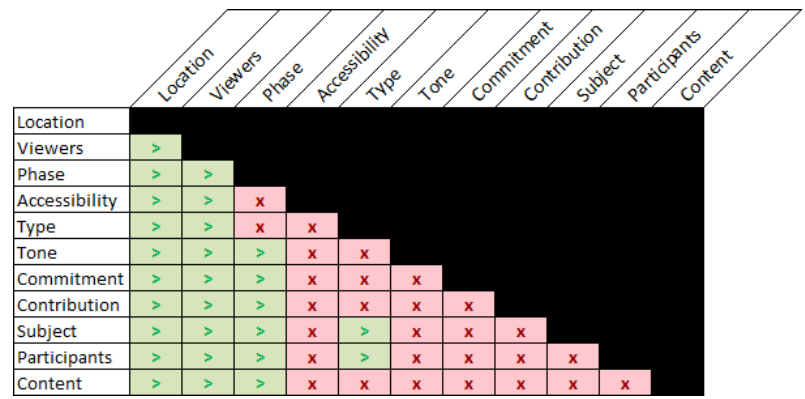

failed for the information items Subject, Type, Accessibility and Phase $(\mathrm{P}>0.05)$, so for this comparison we cannot conclude anything for these items. For the other items we have applied the Wilcoxon test and we found that we could never conclude that an information item is more important in a lower level of involvement when compared to a higher level of involvement. We could however conclude the opposite on multiple occasions. So, a general trend seems to be that information about the conversation is more important when more involved in the conversation. We have presented the results of the Wilcoxon tests in table IX.

An example of a conclusion we can draw from this table is Commitment is more important when listening to a conversation (Level $1 b$ ) than when overhearing a conversation (Level la) and more important when participating in a conversation 
TABLE IX

COMPARATIVE ANALYSIS - INFORMATION ITEMS



(Level 2) than both when listening to a conversation and when overhearing a conversation. So, in general we can see that knowing about the Commitment is increasingly more important as the level of Involvement increases.

\section{Actions possible on a conversation}

The actions that are possible with respect to a conversation identified in the focus group are the following:

- Joining a conversation

$$
\text { Joining }
$$

- Inviting someone to join a conver- Inviting sation

- Listening to a conversation

Listening

- Dismissing other participants

Dismissing Participants

- Dismissing viewers

\section{Dismissing}

Viewers

- Acquiring the attention of the participants

Acquiring

Attention

- Notifying others of the conversa- Notifying tion

others

An overview of how these actions were rated in the questionnaire is shown in table $\mathrm{X}$.

TABLE $\mathrm{X}$

DEsCRIPTIVE STATISTICS - ACTIONS

\begin{tabular}{|l|c|c|c|c|c|}
\hline \multirow{2}{*}{} & \multicolumn{2}{|c|}{ N } & \multicolumn{3}{c|}{ Interquartile range } \\
\cline { 2 - 6 } & Opinion & No-Opinion & 25 th & 50 th & 75 th \\
\hline Joining & 44 & 0 & $-/+$ & + & ++ \\
\hline Inviting & 44 & 0 & + & + & ++ \\
\hline Listening & 44 & 0 & $-/+$ & + & + \\
\hline Dismissing_Participants & 43 & 1 & - & $-/+$ & + \\
\hline Dismissing_Viewers & 42 & 2 & - & $-/+$ & + \\
\hline Acquiring_Attention & 43 & 1 & $-/+$ & + & ++ \\
\hline Notifying_Others & 42 & 2 & - & + & + \\
\hline
\end{tabular}

When applying the Friedman test on this data set it showed the variables are likely to come from a different distribution $\left(\chi^{2}(6)=51.498, P=0.000\right)$. So, we applied the Wilcoxon test on all pairs of 2 variables in the data set to check if we could conclude anything about their mutual importance. The results of these tests are summarized in table XI.

From this table we may conclude that Inviting is the most important action. We can also conclude that Joining is more important than all the other actions except Acquiring Attention.
TABLE XI

COMPARATIVE ANALYSIS - ACTIONS

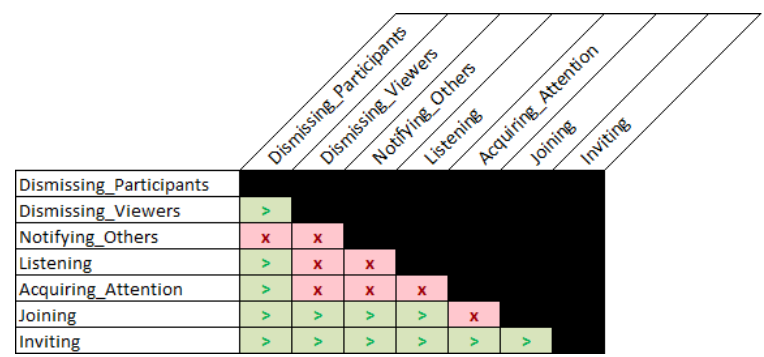

Finally, it is noteworthy that Dismissing Viewers is considered more important than Dismissing Participants.

\section{Benefits and challenges of finished conversations}

Benefits

The benefits of having insight in the finished conversations we found in the focus group are the following:

- Having access to knowledge you Own might otherwise forget Knowledge

- Access to technical knowledge of Technical colleagues

Knowledge

- Acquiring involvement with your Involvement colleagues

- Enjoying your work Enjoying

- Acquiring insight in the commu- Communication nication structure Structure

An overview of how these benefits were rated in the questionnaire is shown in table XII.

TABLE XII

DESCRIPTIVE STATISTICS - BENEFITS OF FINISHED CONVERSATIONS

\begin{tabular}{|l|c|c|c|c|c|}
\hline \multirow{2}{*}{} & \multicolumn{3}{|c|}{ N } & \multicolumn{3}{c|}{ Interquartile range } \\
\cline { 2 - 6 } & Opinion & No-Opinion & 25 th & 50 th & 75 th \\
\hline Own_Knowledge & 44 & 0 & $-/+$ & + & ++ \\
\hline Technical_Knowledge & 44 & 0 & $-/+$ & + & ++ \\
\hline Involvement & 41 & 3 & - & $-/+$ & + \\
\hline Enjoying & 43 & 1 & - & $-/+$ & + \\
\hline Communication_Structure & 43 & 1 & - & $-/+$ & $-/+$ \\
\hline
\end{tabular}

When applying the Friedman test on this data set it showed the variables are likely to come from a different distribution $\left(\chi^{2}(4)=57.331, P=0.000\right)$. So, we applied the Wilcoxon test on all pairs of 2 variables in the data set to check if we could conclude anything about their mutual importance. The results of these tests are summarized in table XIII.

From this table we may conclude that Own Knowledge and Technical Knowledge are more important than Communication Structure, Enjoying and Involvement.

\section{Challenges}

The challenges of having insight in the finished conversations we found in the focus group are the following: 
TABLE XIII

COMPARATIVE ANALYSIS - BENEFITS OF FINISHED CONVERSATIONS



- It can be distracting from the current Distracting work activities

- The context of the conversation can Context be unclear

- A lack of control for the people Lack of whose conversations are overheard Control

An overview of how these challenges were rated in the questionnaire is shown in table XIV.

TABLE XIV

Descriptive StATISTICS - ChALLENGES OF FINISHED CONVERSATIONS

\begin{tabular}{|l|c|c|c|c|c|}
\hline \multirow{2}{*}{} & \multicolumn{2}{|c|}{ N } & \multicolumn{3}{c|}{ Interquartile range } \\
\cline { 2 - 6 } & Opinion & No-Opinion & 25 th & 50 th & 75 th \\
\hline Distracting & 44 & 0 & -- & - & + \\
\hline Context & 44 & 0 & $-/+$ & + & ++ \\
\hline Lack_Of_Control & 43 & 1 & $-/+$ & + & ++ \\
\hline
\end{tabular}

When applying the Friedman test on this data set it showed the variables are likely to come from a different distribution $\left(\chi^{2}(2)=31.533, P=0.000\right)$. So, we applied the Wilcoxon test on all pairs of 2 variables in the data set to check if we could conclude anything about their mutual importance. The results of these tests are summarized in table $\mathrm{XV}$.

TABLE XV

COMPARATIVE ANALYSIS - ChALLENGES OF FINISHED CONVERSATIONS

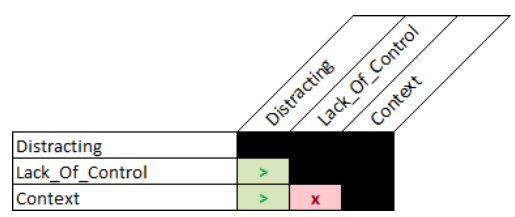

From this table we may conclude that both Context and Lack Of Control are rated as more important challenges than Distracting.

\section{Discussion}

In the previous section we have presented the findings of the study we performed. In this section we will first reflect on the results and subsequently discuss limitations of the methods of data collection we used.

\section{Benefits and challenges of overhearing conversations}

In the previous section we have reported on the benefits and challenges of overhearing conversations. In these findings we can see that in general both the benefits and the challenges are rated as important (all but one have a median of ' + ' in both cases). Therefore further research into the support of overhearing conversations for GSE teams is warranted, however the challenges should be carefully considered. In this consideration, the two challenges rated as most important, Distracting and Lack Of Context, should be addressed with particular rigor.

\section{Relevant information about conversations}

We have also reported on the information items that are important with respect to conversations. In the findings we see that the relative importance of information items is different in the three different levels of involvement. We can also see that the Subject of the conversation is the only information item to be among the most important information items in each level of involvement. Similarly we can see that Location is among the lowest rated items in each level of involvement. Finally, it is also noteworthy that, in general, information items seem to gain importance as the involvement of an actor in the conversation increases.

\section{Possible actions with respect to conversations}

We have shown the findings regarding the actions that are important to be able to do with respect to conversations. In the analysis of these we see that Joining conversations and Inviting others into a conversation are rated as most important. So, with respect to the actions it seems that adding people to a conversations is more important than dismissing them.

\section{Benefits and Challenges of finished conversations}

We have also reported on the benefits and challenges of having access to finished conversations. The main benefits identified here are having access to one's own knowledge and having access to the technical knowledge discussed in the conversations of others. Therefore, we feel it is important to find out how to extract data from conversations to make these easily searchable and help exploit these two benefits. With respect to the challenges it is noteworthy that the interquantile range of the rating of Distracting is quite wide. Some of the participants in the questionnaire seem to find being distracted by having access to finished conversations to be a relatively large problem while others find it relatively unimportant. This difference could very well be related to the level of discipline these people possess. In general, however, we can conclude that both Lack Of Control and Context are rated as more important challenges than Distracting.

\section{Limitations}

We provided a quite thorough discussion regarding the limitations of the methods of data collection we used in the description of the research site and method. In this description we also discussed what we did to deal with these challenges. However, there are still some issues that did not fit in that section or need to be emphasized. 
Firstly, even though most participants were used to working from home and we had a few participants from Belgium and the USA, most people cooperated mainly in a co-located fashion on a daily basis. Therefore it is possible that the limited exposure to working distributed from their colleagues caused items to be misrated in the questionnaire. For example, as a benefit of overhearing conversations, having insight in the communication structure of the team is rated relatively low. This could of course indicate this is actually the case, however it could also be caused by the fact that participants already knew their colleagues very well, causing having insight into the communication structure to be less important.

A second limitation has to do with the actual size of the sample. For practical reasons, we performed one focus group and sent the questionnaire to 47 people. In this case, as in all cases, increasing the sample size would increase the reliability of the data. For example if the sample size of the questionnaire is increased more Friedman and Wilcoxon tests would provide significant results, allowing for more conclusions to be drawn.

A third limitation has to do with the sample itself. For the focus group we selected all participants from the Delft location, again for practical reasons. Next to this, the people that participated in the focus group also participated in the questionnaire. Both these decisions may have created a bias in the results.

A fourth limitation is that all participants worked for a single department of a single company. When doing research in an attempt to draw conclusions applicable for the general field of Software Engineering, the sample should resemble that population as accurately as possible. In general we can state that with a larger sample and a more accurate resemblance of the population more externally valid conclusions can be drawn.

Finally, in our analysis of the questionnaire data we used Fishers' Least Significant Difference method to help reduce the number of false positives caused by the pair-wise comparison of all items. In comparison with other methods which aim to accomplish this Fishers' LSD is fairly liberal. We chose to use a fairly liberal method because of the explanatory character of this research. Examples of more conservative methods are: Tukey's Honestly Significant Difference, Scheffe's test and the Bonferroni adjustment.

\section{CONCLUSiOnS}

In this paper we have reported on the evaluation of being able to overhear conversations of your colleagues in the field of Software Engineering in an industrial case setting. We are interested in an evaluation of the value of overhearing conversations of your colleagues because we wish to find out whether researching how to enable overhearing conversations in a distributed setting is worth pursuing. Our main findings are the following:

- All identified benefits and challenges are important

- Distracting and Lack of Context are the most important challenges of overhearing conversations

- Knowing the subject of a conversation is very important
- Knowing the location of a conversation is generally unimportant

- Information about a conversation in general gains importance as the actor is more involved in that conversation

- Adding participants to a conversation is more important than removing them

- It is important to be able to search through past conversations

- Lack of Control and Lack of Context are the most important challenges of having access to finished conversations

Following from these findings, the main contributions of this paper are:

- The conclusion that research about support for conversations in GSE is worth pursuing

- Insights on important aspects to consider when researching support for conversations in GSE

Directly following from these contributions future work will concern researching how to support the overhearing of conversations in a distributed setting. To do this we will measure how the overhearing of conversations is experienced in such a setting by enabling this with technological support. We will use the data, findings and insights reported in this paper as a starting point for this.

\section{REFERENCES}

[1] E. Carmel, Global software teams: collaborating across borders and time zones. Upper Saddle River: Prentice Hall PTR, 1999.

[2] J. Herbsleb and D. Moitra, "Guest Editors' Introduction: Global Software Development," IEEE Software, vol. 18, no. 2, pp. 16-20, 2001.

[3] J. Herbsleb, "Global Software Engineering: The Future of Sociotechnical Coordination," in Proceedings of the IEEE 2007 Workshop on the Future of Software Engineering. IEEE Computer Society Press, 2007, pp. 188-198.

[4] The Dieringer Research Group Inc., "Telework Trendlines 2009: A Survey Brief by WorldatWork," 2009.

[5] R. Grinter, J. Herbsleb, and D. Perry, "The geography of coordination: dealing with distance in R\&D work," in Proceedings of the ACM SIGGROUP 1999 International Conference on Supporting Group Work. ACM Press, 1999, pp. 306-315.

[6] D. Damian and D. Moitra, “Guest Editors' Introduction: Global Software Development: How Far Have We Come?" IEEE Software, vol. 23, no. 5, pp. 17-19, 2006.

[7] C. Ebert and P. De Neve, "Surviving global software development," IEEE Software, vol. 18, no. 2, pp. 62-69, 2001.

[8] J. Herbsleb and R. Grinter, "Architectures, coordination, and distance: Conway's law and beyond," IEEE Software, vol. 16, no. 5, pp. 63-70, 1999.

[9] E. Carmel and R. Agarwal, "Tactical approaches for alleviating distance in global software development," IEEE Software, vol. 18, no. 2, pp. 22-29, 2001.

[10] I. Harpaz, "Advantages and disadvantages of telecommuting for the individual, organization and society," International Journal of Productivity and Performance Management, vol. 51, no. 2, pp. 74-80, 2002.

[11] B. Hesse and C. Grantham, "Electronically Distributed Work Communities: Implications for Research on Telework," Internet Research, vol. 1, no. 1, pp. 4-17, 1991.

[12] J. Pratt, "Myths and Realities of Working at Home: Characteristics of Homebased Business Owners and Telecommuters," National Technical Information Service, Tech. Rep., 1993.

[13] K. Schmidt, "The Problem with 'Awareness': Introductory Remarks on 'Awareness in CSCW',' Computer Supported Cooperative Work, vol. 11, no. 3-4, pp. $285-298,2002$.

[14] A. Syri, "Tailoring cooperation support through mediators," in Proceedings of the 1997 European Conference on Computer Supported Cooperative Work. Kluwer Academic Publishers, 1997, pp. 157-172. 
[15] P. Dourish and V. Bellotti, "Awareness and Coordination in Shared Workspaces," in Proceedings of the ACM 1992 Conference on Computer Supported Cooperative Work. ACM Press, 1992, pp. 107-114.

[16] C. Gutwin, R. Penner, and K. Schneider, "Group awareness in distributed software development," in Proceedings of the ACM 2004 Conference on Computer Supported Cooperative Work. ACM Press, 2004, pp. 72-81.

[17] J. Fogarty, S. Hudson, C. Atkeson, D. Avrahami, J. Forlizzi, S. Kiesler, J. Lee, and J. Yang, "Predicting human interruptibility with sensors," ACM Transactions on Computer-Human Interaction, vol. 12, no. 1, pp. $119-146,2005$.

[18] J. Herbsleb and A. Mockus, "An empirical study of speed and communication in globally distributed software development," IEEE Transactions on Software Engineering, vol. 29, no. 6, pp. 481-494, 2003.

[19] T. Allen, Managing the flow of technology. MIT press, 1977.

[20] J. Olson and S. Teasley, "Groupware in the wild: lessons learned from a year of virtual collocation," in Proceedings of the ACM 1996 Conference on Computer Supported Cooperative Work. ACM Press, 1996, pp. 419427.

[21] D. Perry, N. Staudenmayer, and L. Votta, "People, organizations, and process improvement," Software, IEEE, vol. 11, no. 4, pp. $36-45$, Jul 1994.

[22] K. Dullemond, B. van Gameren, and R. van Solingen, "Virtual Open Conversation Spaces: Towards Improved Awareness in a GSE Setting," in Proceedings of the 2010 International Conference on Global Software Engineering. IEEE Computer Society Press, 2010, pp. 247-256.

[23] J. Espinosa and E. Carmel, "The impact of time separation on coordination in global software teams: a conceptual foundation," Software Process: Improvement and Practice, vol. 8, no. 4, pp. 249-266, 2003.

[24] S. Greenberg and C. Gutwin, "A descriptive framework of workspace awareness for real-time groupware," Computer Supported Cooperative Work, vol. 11, no. 3-4, pp. 411-446, 2002.

[25] Y. Ren and R. Kraut, "A Simulation for Designing Online Community: Member Motivation, Contribution, and Discussion Moderation.” Manuscript in preparation: Retrieved from: http://www.cs.cmu. edu/ kraut on June $2^{\text {nd }} 2011$.

[26] A. Webber, "What's so new about the new economy?" Harvard Business Review, 1993.

[27] T. Erickson, D. Smith, W. Kellogg, M. Laff, J. Richards, and E. Bradner, "Socially translucent systems: social proxies, persistent conversation, and the design of babble," in Proceedings of the SIGCHI 1999 Conference on Human Factors in Computing Systems. ACM Press, 1999, pp. $72-79$.

[28] E. Wynn, "Office conversation as an information medium," Ph.D. thesis, University of California, Berkely, 1979.

[29] S. Greenberg and M. Rounding, "The notification collage: posting information to public and personal displays," in Proceedings of the SIGCHI 2001 Conference on Human Factors in Computing Systems. ACM Press, 2001, pp. 514-521.
[30] M. Sosa, S. Eppinger, M. Pich, D. McKendrick, and S. Stout, "Factors that influence technical communication in distributed product development: an empirical study in the telecommunications industry," IEEE Transactions on Engineering Management, vol. 49, no. 1, pp. 45-58, 2002.

[31] K. R. McCord, "Managing the integration problem in concurrent engineering," Master thesis, Massachusetts Institute of Technology, 1993.

[32] R. Kraut, R. Fish, R. Root, and B. Chalfonte, "Informal communication in organizations: Form, function, and technology," in Human reactions to technology: Claremont Symposium on Applied Social Psychology. Sage Publications, 1990, pp. 145-199.

[33] Exact Holding N.V., "Annual Report 2010," 2010.

[34] K. Dullemond and B. van Gameren, "Communico: Overhearing conversations in a virtual office," in Proceedings of the ACM 2011 conference on Computer supported cooperative work. ACM, 2011, pp. 577-578.

[35] K. Dullemond, B. van Gameren, and R. van Solingen, "Overhearing Conversations in Global Software Engineering - Requirements and an Implementation," in Proceedings of the 2011 International Conference on Collaborative Computing: Networking, Applications and Worksharing. IEEE, 2011.

[36] A. Avritzer and D. J. Paulish, "A comparison of commonly used processes for multi-site software development," in Collaborative Software Engineering, I. Mistrk, A. van der Hoek, J. Grundy, and J. Whitehead, Eds. Springer Berlin Heidelberg, 2010, pp. 285-302.

[37] J. Kontio, L. Lehtola, and J. Bragge, "Using the focus group method in software engineering: Obtaining practitioner and user experiences," Empirical Software Engineering, International Symposium on, vol. 0, pp. 271-280, 2004.

[38] J. Langford and D. McDonaugh, Focus Groups: Supporting Effective Product Development. Taylor and Francis, 2003.

[39] K. D. Bailey, Methods of Social Research. New York: Free Press, 1978.

[40] C. M. Judd, E. R. Smith, and L. H. Kidder, Research Methods in Social Relations. Harcourt Brace Jovanovich, 1991.

[41] A. Fink, How to manage, analyze, and interpret survey data, 2nd ed. London: Sage, 2003.

[42] K. Kelley, B. Clark, V. Brown, and J. Sitzia, "Good practice in the conduct and reporting of survey research." International journal for quality in health care : journal of the International Society for Quality in Health Care / ISQua, vol. 15, no. 3, pp. 261-6, Jun. 2003. [Online]. Available: http://www.ncbi.nlm.nih.gov/pubmed/12803354

[43] B. Gillham, "Developing a questionnaire," 2000.

[44] R. Likert, "A technique for the measurement of attitudes." Archives of psychology, vol. 22, no. 140, pp. 1-55, 1932.

[45] R. Fisher, "The design of experiments." 1935. 